\title{
SURVEY OF AIRBORNE PARTICULATE MATTER CONCENTRATION AT A MARBLE PROCESSING FACILITY - WORKERS' EXPOSURE ASSESSMENT
}

\author{
DIAPOULI E. ${ }^{1, *}$ \\ PAPAMENTZELOPOULOU A. ${ }^{2}$ \\ CHALOULAKOU A. ${ }^{2}$
}

\author{
${ }^{1}$ N.C.S.R. "Demokritos", \\ Institute of Nuclear \& Radiological Sciences \& Technology, \\ Energy \& Safety, 15310 Ag. Paraskevi, Greece \\ ${ }^{2}$ N.T.U.A., School of Chemical Engineering \\ Zographos Campus, 15773, Athens, Greece
}

Received: $12 / 04 / 13$

Accepted: 16/05/13 *to whom all correspondence should be addressed: e-mail: Idiapouli@ipta.demokritos.gr

\begin{abstract}
The scope of the present work was to examine exposure to airborne particulate matter (PM) at a marble cutting and treatment facility. Measurements were conducted inside all sections of the facility, as well as at selected outdoor locations. $\mathrm{PM}_{10}$ concentrations were monitored continuously, with a 1min time resolution, by the use of DustTrak (Model 8520, TSI, Inc.).

Mean $\mathrm{PM}_{10}$ concentration levels during cutting operations were measured equal to $997 \mu \mathrm{g} \mathrm{m}^{-3}$, when all machines were in use and $710 \mathrm{\mu g} \mathrm{m}^{-3}$, when only half of the machines were functioning. Higher levels were measured at the artistic department, where marble is cut and processed manually (mean $\mathrm{PM}_{10}$ concentration equal to 3,860 during a heavy cutting procedure and $1,000 \mu \mathrm{g} \mathrm{m}^{-3}$ during a light duty period). When sampling was conducted next to the workers during the cutting process, mean personal exposure reached up to $63,000 \mu \mathrm{g} \mathrm{m}^{-3}$. The use of water during cutting operation was found to effectively decrease PM emissions. Significant concentrations were also measured at the different administrative offices. The highest levels (mean concentration equal to $220 \mu \mathrm{g} \mathrm{m}^{-3}$ ) were measured at the accounting office which is located at ground level, in close vicinity to the cutting section.
\end{abstract}

KEYWORDS: air quality, workers' exposure, suspended particles (PM), marble processing.

\section{INTRODUCTION}

Exposure to airborne particulate matter (PM) has been associated with a number of adverse health effects, including cardiovascular and respiratory diseases (Vedal et al., 2009; Pope et al., 2004). Fine particles (with aerodynamic diameters less than $2.5 \mu \mathrm{m}$ ) and ultrafine particles (with diameters below $0.1 \mu \mathrm{m}$ ) have been generally considered more detrimental for human health, due to their smaller size allowing for a deeper penetration into the respiratory system, and their higher concentration of toxic compounds (Kappos et al., 2004; Ibald-Mulli et al., 2002). Nevertheless, recently evidence has emerged that coarse particles are also related to adverse lung responses and cardiovascular episodes and should be considered in epidemiological studies and for regulatory purposes (Brunekreef and Forsberg, 2005). These particles often originate from natural sources (sea salt, pollen or other biological material, soil dust) but they may also be related to anthropogenic activities, such as demolition of buildings, crushing or grinding operations, emissions through windblown dust from piles of industrial or construction material or road dust resuspension by traveling vehicles (Wilson and Suh, 1997).

Occupational exposure presents a special interest, since the processes applied may lead to emission of particles containing hazardous chemical constituents that are not typically found in the ambient atmosphere. One of the main industrial activities related with exposure to coarse particles is mining and milling of stone. Crushed stone production involves physical and mechanical processes 
that may lead to workers' exposure to airborne dusts containing a variety of minerals. Occupational exposure levels and associated workers' diseases have drawn researchers' attention globally since more than 20 years (Costello et al., 1995; Kullman et al., 1995).

The scope of the present work was to examine exposure to PM at a marble cutting and treatment facility. The Greek marble sector employs more than 60,000 persons, engaging mainly in quarrying, cutting and/or treatment and manufacture of art works. Many of the processes involved have been associated with a number of occupational diseases, such as hearing loss and respiratory disorders. Several studies have reported increased exposures of marble workers to particulate matter, as well as exposures to heavy metals and crystalline silica, which is classified by IARC (1997) as a known human carcinogen (Scarselli et al., 2008; Yassin et al., 2005; Golbabaei et al., 2004; Yaghi and Abdul-Wahab, 2003; Guenel et al., 1989). The present study is the first effort to assess exposure to $\mathrm{PM}$ in the Greek marble processing sector.

\section{METHODS}

The under study facility is located in the Koropi Industrial Zone, at the Eastern Part of Attica, southeast of Athens Metropolitan Area and in close vicinity to a major motorway (Attica Tollway) and the airport (Figure 1). The facility includes the marble cutting and treatment sections, the exhibition centre, as well as administrative offices. Measurements were conducted inside all sections of the marble production process (cutting, artistic and sandblasting departments) and at selected indoor and outdoor locations of the administration building. All sampling was carried out during May 2009. Two measurements were conducted at each indoor and outdoor location, covering working hours of different days.

$\mathrm{PM}_{10}$ concentration was monitored continuously, with a 1-min time resolution, by the use of DustTrak Aerosol Monitor (Model 8520, TSI, Inc.). DustTrak measures particle concentrations corresponding to $\mathrm{PM}_{10}, \mathrm{PM}_{2.5}, \mathrm{PM}_{1.0}$ or respirable size fractions. It is a portable, battery-operated laser photometer which provides real-time digital readout and built-in data logger. DustTrak's nominal flow rate is 1.7 I $\min ^{-1}$ and it is obtained by an internal pump integral to the sampler. The monitor is factory-calibrated for the respirable fraction of standard ISO 12103-1, A1 test dust (Arizona Test Dust), which is representative for a wide variety of aerosols. It measures concentrations in the range $0.001-100$ $\mathrm{mg} \mathrm{m}^{-3}$, with a resolution of $0.1 \%$ of the reading or $0.001 \mathrm{mg} \mathrm{m}^{-3}$. Before each measurement, the instrument was zeroed and its flow rate was checked.

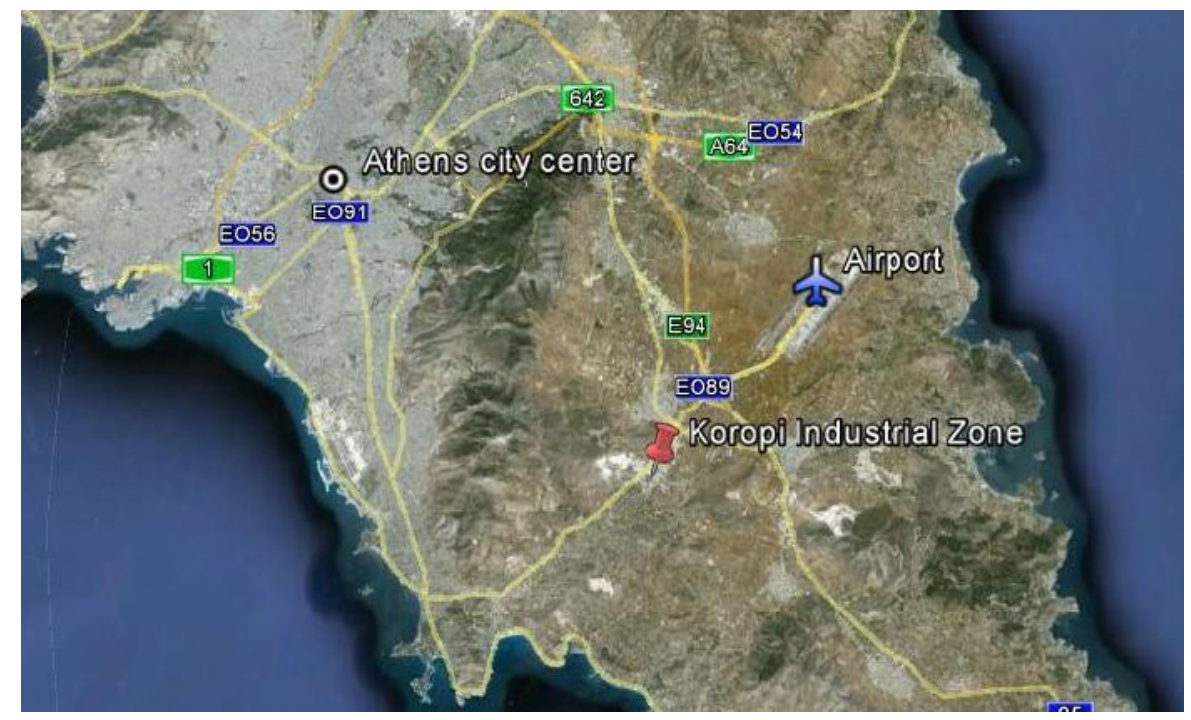

Figure 1. Map the Attica region, including Koropi Industrial Zone and its position relative to Athens Metropolitan Area and Athens International Airport

\section{RESULTS}

\subsection{Marble cutting and treatment sections}

Mean $\mathrm{PM}_{10}$ concentrations measured at the different cutting and treatment sections are presented in Figure 2. The highest levels were measured at the artistic department, where marble is cut and 
processed manually. Especially during heavy cutting procedures, the measured $\mathrm{PM}_{10}$ levels greatly surpassed the concentrations observed in all other sites. The light-duty period levels may be considered representative of mean 8-hr daily exposure of workers in this department. A characteristic example of $\mathrm{PM}_{10}$ concentrations variation during a 20 -min heavy cutting procedure is presented in Figure 3 . The monitor was placed next to the worker engaged in marble cutting during the first $5 \mathrm{~min}$ of the measurement, simulating his personal exposure. For the remaining monitoring period it was placed at a distance from the particle source, in order to measure mean concentrations in the department. It is clearly seen that the worker's personal exposure during cutting processes may be much greater than the measured mean indoor concentration levels (mean exposure calculated equal to $63,000 \mu \mathrm{g} \mathrm{m}^{-3}$ ).

The main cutting department comprises 4 cutting machines which operate with the use of water, in order to minimize particle emission. The results indeed suggest that this control measure is effective, since the measured $\mathrm{PM}_{10}$ concentrations are lower in relation to manual cutting processes, even when all 4 machines are in operation. An example of $\mathrm{PM}_{10}$ concentrations variation during full operation of cutting machines in presented in Figure 4.

Regarding the sandblasting department, it is located at a distance from the remaining facility's sections, while workers in the chamber use personal protective equipment. During the measurements, the PM monitor was placed at a distance of $10 \mathrm{~m}$ from the chamber, in order to avoid overloading of the instrument. The observed concentrations are indicative of the levels in the area surrounding the chamber.

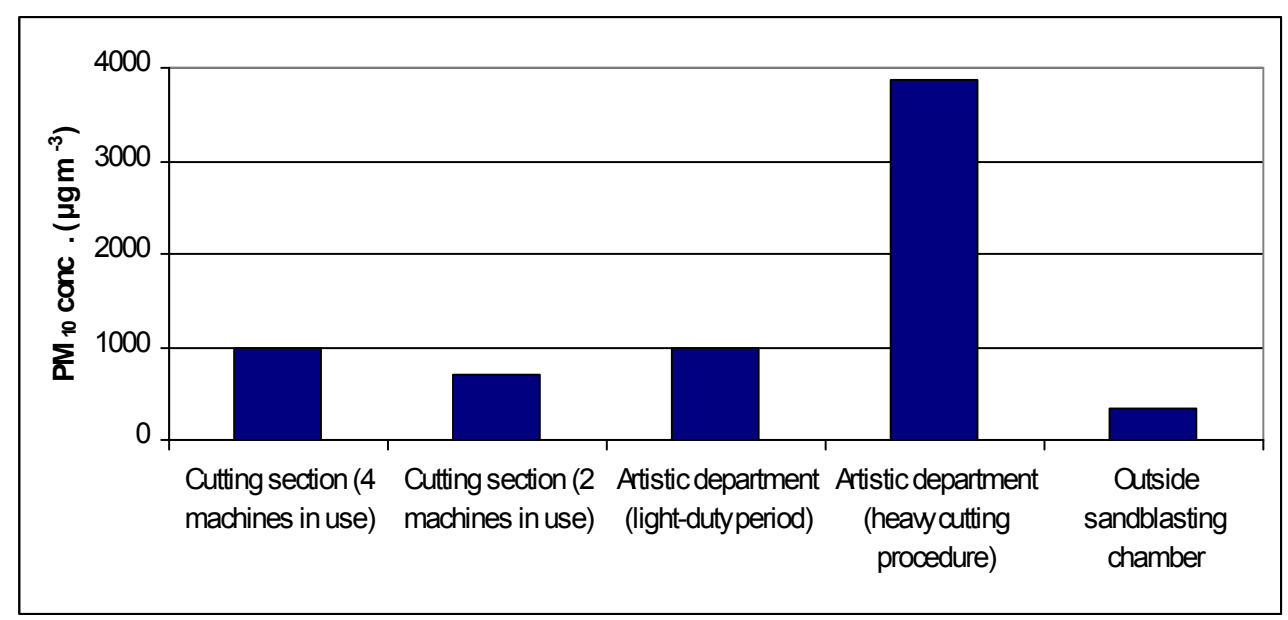

Figure 2. Mean $\mathrm{PM}_{10}$ concentration levels at different cutting and treatment departments

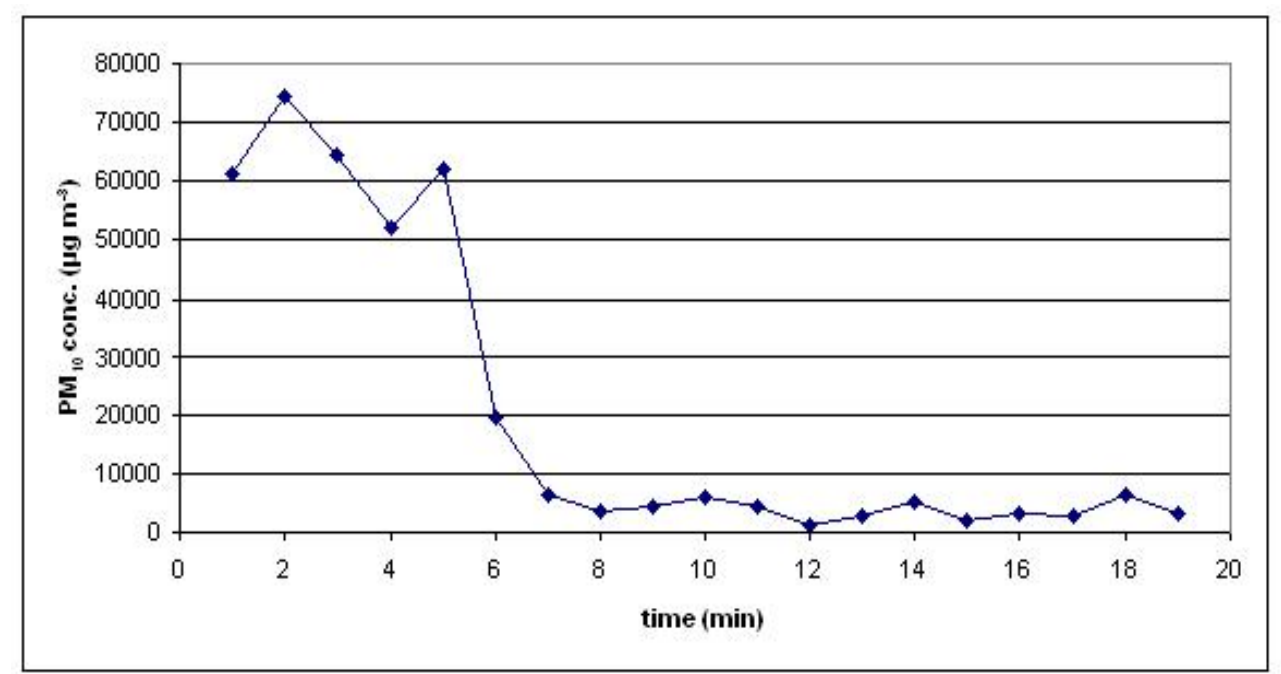

Figure 3. Variation of $\mathrm{PM}_{10}$ concentrations during heavy cutting procedure at the artistic department 


\subsection{Administration building}

Significant concentrations were also measured at the administrative offices. Mean $\mathrm{PM}_{10}$ concentration levels measured at different indoor and outdoor locations of the administrative buildings are presented in Figure 5. The highest levels were measured at the accounting office which is located at ground level. The office is naturally ventilated and is located in close vicinity to the cutting section. Lower concentrations were measured inside the remaining ground level offices which are ventilated mechanically and in the $1^{\text {st }}$ floor offices, which are naturally ventilated but face the outer part of the facility. Ambient levels in the premises of the facility were also elevated.

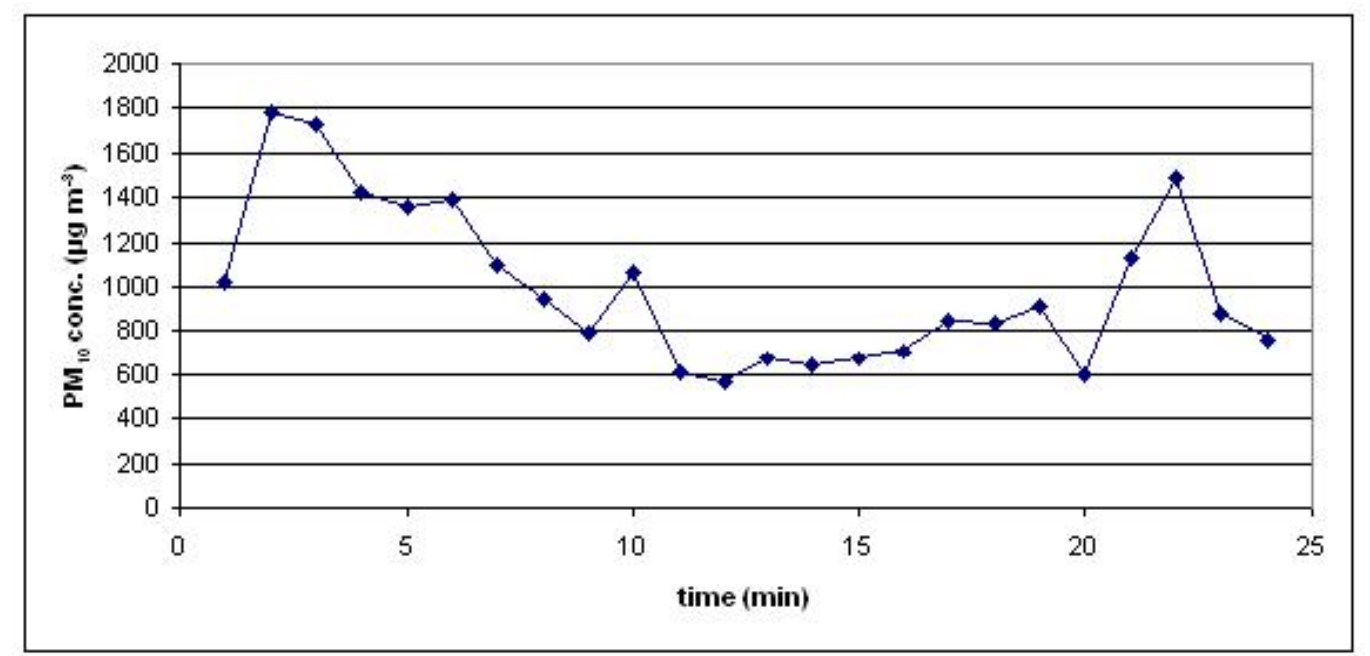

Figure 4. Variation of $\mathrm{PM}_{10}$ concentrations in the cutting department, with all 4 cutting machines in use

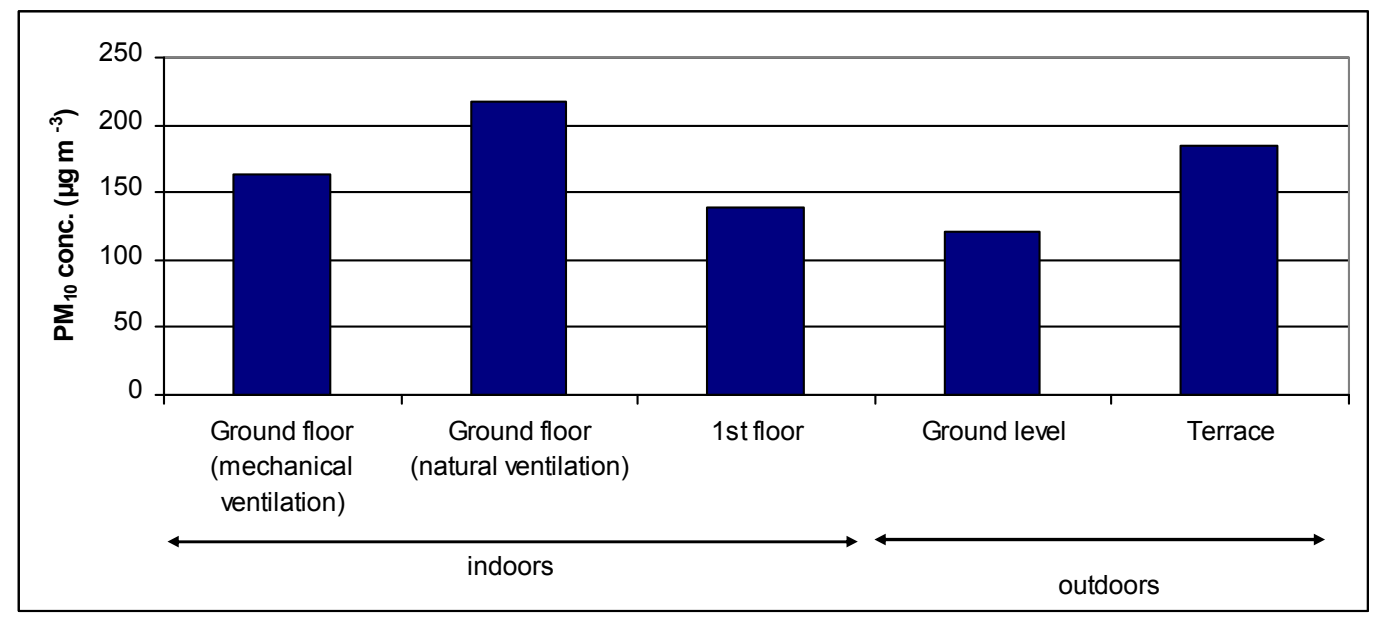

Figure 5. Mean $\mathrm{PM}_{10}$ concentration levels at the administration building

\section{CONCLUSIONS}

The present study is the first effort to assess exposure to PM in the Greek marble processing sector. The concentration levels measured at the different operational working environments were significant but did not exceed the 8-hr occupational limit value for non-reactive inhalable dust $\left(10,000 \mathrm{\mu g} \mathrm{m}^{-3}\right)$. PM concentrations were lower in automatic processing, where water was used to minimize particle emissions. Manual processing of marble on the other hand was found to lead to increased PM emissions. Workers' short-term personal exposure during manual treatment in the artistic department was measured more than 10 times higher than the mean concentrations recorded inside the department, clearly highlighting the need for protective equipment. Regarding the office environments and ambient levels at the site, the E.U. 24-hr limit value for ambient air (50 $\mu \mathrm{g} \mathrm{m}^{-3}$ ) was significantly exceeded. 
This survey has provided the first results on occupational exposure in a Greek marble processing facility. Working environments and specific processes associated with increased exposures have been identified. Additional monitoring and chemical analysis of suspended particles should be undertaken at a next step in order to fully characterize and assess occupational exposure and to develop appropriate mitigation measures for the workers' protection.

\section{REFERENCES}

1. Brunekreef B. and Forsberg B. (2005), Epidemiological Evidence of Effects of Coarse Airborne Particles on Health, Eur. Respir. J., 26, 309-318.

2. Costello J., Castellan R.M., Swecker G.S. and Kullman G.J. (1995), Mortality of a Cohort of U.S. workers Employed in the Crushed Stone Industry, 1940-1980, Am. J. Ind. Med., 27, 625-640.

3. Ibald-Mulli A., Wichmann H.-E., Kreyling W. and Peters A. (2002), Epidemiological Evidence of Health Effects on Ultrafine Particles, J. Aerosol Med., 15(2), 189-201.

4. Golbabaei F., Barghi M.-A. and Sakhaei M. (2004), Evaluation of Workers' Exposure to Total, Respirable and Silica Dust and the Related Health Symptoms in Senjedak Stone Quarry, Iran, Ind. Health, 42, 29-33.

5. Guenel P., Breum N.O. and Lynqe E. (1989), Exposure to Silica Dust in the Danish Stone Industry, Scand. J. Work. Environ. Health, 15,147- 153.

6. International Agency for Research on Cancer (1997), Silica, some Silicates, Coal Dust and ParaAramid Fibrils, IARC Monogr. Eval. Carcinog. Risk Hum., 68, 42-242.

7. Kappos A.D., Bruckmann P., Eikmann T., Englert N., Heinrich U., Hoppe P., Koch E., Krause G.H.M., Kreyling W.G., Rauchfuss K., Rombout P., Schulz-Klemp V., Thiel W.R. and Wichmann H.E. (2004), Health Effects of Particles in Ambient Air, Int. J. Hyg. Environ. Health, 207, 399-407.

8. Kullman G.J., Greife A.L., Costello J. and Hearl F.J. (1995), Occupational Exposures to Fibers and Quartz at 19 Crushed Stone Mining and Milling Operations, Am. J. Ind. Med., 27, 641-660.

9. Pope III C.A., Burnett R.T., Thurston G.D., Thun M.J., Calle E.E., Krewski D. and Godleski J.J (2004), Cardiovascular Mortality and Longterm Exposure to Particulate Air Pollution: Epidemiological Evidence of General Pathophysiological Pathways of Disease, Circulation, 109, 71-77.

10. Scarselli A., Binazzi A. and Marinaccio A. (2008), Occupational Exposure to Crystalline Silica: Estimating the Number of Workers Potentially at High Risk in Italy, Am. J. Ind. Med., 51, 941-949.

11. Vedal S., Hannigan M.P., Dutton S.J., Miller S.L., Milford J.B., Rabinovitch N., Kim S.-Y. and Sheppard L. (2009), The Denver Aerosol Sources and Health (DASH) Study: Overview and Early Findings, Atmos. Environ., 43, 1666-1673.

12. Wilson W.E. and Suh H.H. (1997), Fine Particles and Coarse Particles: Concentration Relationships Relevant to Epidemiologic Studies, J. Air Waste Manage. Assoc., 47, 1238-1249.

13. Yaghi B. and Abdul-Wahab S.A. (2003), Assessment of Lead, Zinc, Copper, Nickel and Chromium in Total Suspended Particulate Matter from the Workplace in Al-Rusayl Industrial Estate, Oman, $J$. Environ. Monit., 5, 950-952.

14. Yassin A., Yebesi F. and Tingle R. (2005), Occupational Exposure to Crystalline Silica Dust in the United States, 1988-2003, Environ. Health Persp., 113, 225-260. 